\title{
Morbidity and mortality of COVID-19 negatively associated with the frequency of consanguineous marriages, an ecologic study
}

\author{
Mostafa Saadat ${ }^{*}$ (i)
}

\begin{abstract}
Background: Union between second cousins and closer relatives is called consanguineous marriage. Consanguineous marriage is associated with increased risk of autosomal recessive diseases and several multifactorial traits. In order to evaluate the association between prevalence/mortality of COVID-19 and the frequency of consanguineous marriage, the present ecologic study was carried out. For the present study, data of prevalence (per $10^{6}$ people) and mortality (per $10^{6}$ people) and number of performed laboratory diagnostic test (per $10^{6}$ people) of COVID-19 disease at four time points (December 2020; March, August and October 2021) of 65 countries were used.

Results: Univariable correlation and generalized estimating equation analysis were used. In analysis, prevalence and mortality of COVID-19 were used as dependent variables and human development index, number of performed diagnosis test and the mean of inbreeding coefficient (a-value) were introduced into model as covariates, and time point was used as a factor in analysis. The square root (SR) of prevalence $(P=0.008)$ and SR-mortality $(P<0.001)$ of COVID-19 negatively associated with the log-transformed of a-value.
\end{abstract}

Conclusions: The present finding means that in countries with high levels of consanguineous marriages, the prevalence of COVID-19 and mortality due to COVID-19 were lower than countries having low level of marriage with relatives.

Keywords: Consanguineous marriage, COVID-19, Ecologic study

\section{Background}

In genetics, union between second cousins and closer relatives is called consanguineous marriage [1]. Previously it has been shown that consanguineous marriage is a long-standing social custom which depends with numerous factors, such as religious, socio-economic and demographic variables [2-4]. The frequency of consanguineous marriage has geographical distribution; it has high prevalence in several Asia and Africa countries. Iranian populations showed high levels of consanguineous marriages [5-7].

*Correspondence: saadat@shirazu.ac.ir

Department of Biology, College of Sciences, Shiraz University, 71467-13565 Shirazm, Iran
Numerous studies have shown that this type of marriage is associated with increased risk of autosomal recessive diseases and several multifactorial traits $[1$, $8-15]$. It is well established that primary immunodeficiency diseases are genetically heterogeneous group and are associated with parental consanguinity [16]. There is significant association between parental consanguineous marriage and the risk of some infections $[17,18]$. There is about one-fifth of the world's population living in countries where marriage with biological relatives is prevalent. Therefore, for countries with high prevalence of consanguineous marriage, the association between frequency of consanguineous marriage and the Coronavirus Disease 2019 (COVID-19) is highly important. To the best of our knowledge, there is no study regarding the 
above-mentioned association; therefore, the present ecologic study was carried out.

\section{Methods}

Prevalence (per $10^{6}$ people) and mortality (per $10^{6}$ people) and number of performed laboratory diagnostic test (per $10^{6}$ people) of COVID-19 disease at four time points (December 31, 2020; March 19, 2021; August 31, 2021 and October 25, 2021) were obtained from the Web site www.worldometers.info/coronavirus (Table 1).

Very recently importance of socioeconomic position and Human Development Index (HDI) in study of COVID-19 has been reported [19-21]. The HDI reflects three major dimensions of human development, life expectancy at birth, education and the gross national income (PPP) per capita. Countries with higher life expectancy, income and educational levels have higher HDI values. The HDI values are calculated annually and reported by the United Nations Development Program's Human Development Report Office. The latest report (2019) was used in the present analysis as a potential confounder.

The inbreeding coefficient means the probability that an individual has received both alleles of a pair from an identical ancestral allele and shown by $F$-value. The $F$-value, for double first cousins, first cousins, first cousin once removed, second cousins, and unrelated marriages, was $1 / 8,1 / 16,1 / 32,1 / 64$ and 0 , respectively. The mean of $F$-values which is shown by $\alpha$-value, and it is calculated as $F=\sum \mathrm{PiFi}$, where $\mathrm{Pi}$ and $\mathrm{Fi}$ are frequency and the $F$-value of each marriage type. The $\alpha$-values were estimated from data presented in the Web site www.consang.net.

Data from 65 countries were included in the study. The countries were Afghanistan, Argentina, Australia, Bahrain, Bangladesh, Belgium, Bolivia, Brazil, Canada, Chile, China, Colombia, Costa Rica, Croatia, Cuba, Czech Republic, Ecuador, Egypt, El Salvador, France, Guinea, Honduras, Hungary, India, Indonesia, Iran, Iraq, Ireland, Italy, Japan, Jordan, Kuwait, Lebanon, Libya, Malaysia, Mexico, Mongolia, Morocco, Nepal, Netherlands, Nigeria, Norway, Oman, Pakistan, Panama, Peru, Philippines, Portugal, Qatar, Saudi Arabia, Singapore, Slovakia, Slovenia, South Africa, Spain, Sri Lanka, Sweden, Tunisia, Turkey, United Arab Emirates, UK, Uruguay, USA, Venezuela, and Yemen.

Normality of variables was investigated using Kolmogrov-Smirnov test. If a variable was not distributed normally, its log-transformed or square root-transformed (SR-transformed) was used in statistical analysis. Univariable correlation analysis was used. To overcome the effects of confounders on prevalence/mortality, generalized estimating equation analysis was used. Prevalence/ mortality of COVID-19 was considered as outcome variables, and the $\alpha$-values as well as the potential confounders (number of performed test and HDI) were introduced into model as covariates. It should be noted that time point was used as a factor in analysis. Data were analyzed using SPSS software (version 25; SPSS Inc., Chicago, IL). Statistical analysis was performed using $P<0.05$ as the cutoff point for significant association.

\section{Results}

Normality test showed that HDI has normal distribution. Other variables were not distributed normally. For statistical analysis, the log-transformed of $\alpha$-value, and the SR-prevalence and SR-mortality of COVID-19 and SRnumber of performed test were used.

Table 2 summarizes the correlations between the study variables. It should be noted that almost all of the studies variables had significant correlation with each other. The SR-prevalence $(P<0.001)$ and SR-mortality of COVID-19 $(P<0.001)$ were negatively associated with the log-transformed of $\alpha$-value.

On the other hand, there was significant negative relationship between log-transformed of $\alpha$-value and HDI $(r=-0.618, \mathrm{df}=63, P<0.001)$. In all of the study time points, the SR-prevalence $(\mathrm{P}<0.001)$ and SR-mortality of COVID-19 $(P<0.001)$ were significantly associated with HDI.

In order to neutralized the potential confounding effects of the HDI and number of performed tests on the correlation between $\alpha$-values and epidemiologic parameters, generalized estimating equations were used (Table 3). The construction final models showed that SR-prevalence $(P=0.008)$ and SR-mortality $(P<0.001)$ parameters of COVID-19 negatively associated with the $\log$-transformed of $\alpha$-value.

\section{Discussion}

The current study revealed that in countries with high levels of consanguineous marriages, the prevalence of COVID-19 and mortality due to COVID-19 were lower than countries having low frequency of marriage with relatives. The $\alpha$-value can explain $36 \%$ of the differences observed in the mortality due to COVID-19 between different countries. Although the main finding of the current study is not consistent with previous reports which reported that primary immunodeficiency diseases [16] and risk of infection of tuberculosis and hepatitis [17] positively correlated with consanguineous marriages, it is consistent with the negative association between parental consanguinity and risk of HIV-1 infection [18].

The present finding that countries with high frequency of consanguineous marriages have low prevalence/mortality of COVID-19 might be interpreted by increased number of resistant individuals against 


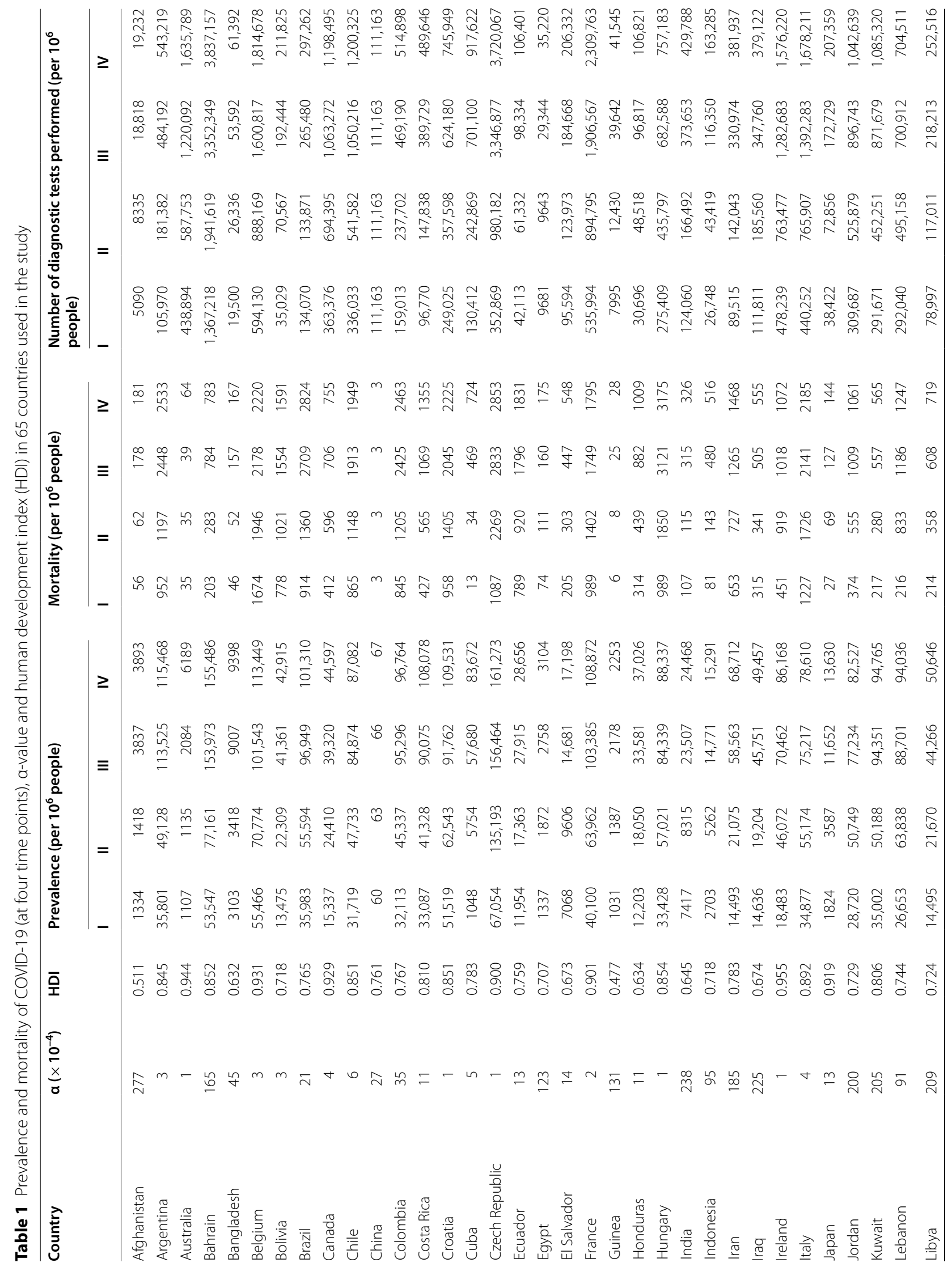




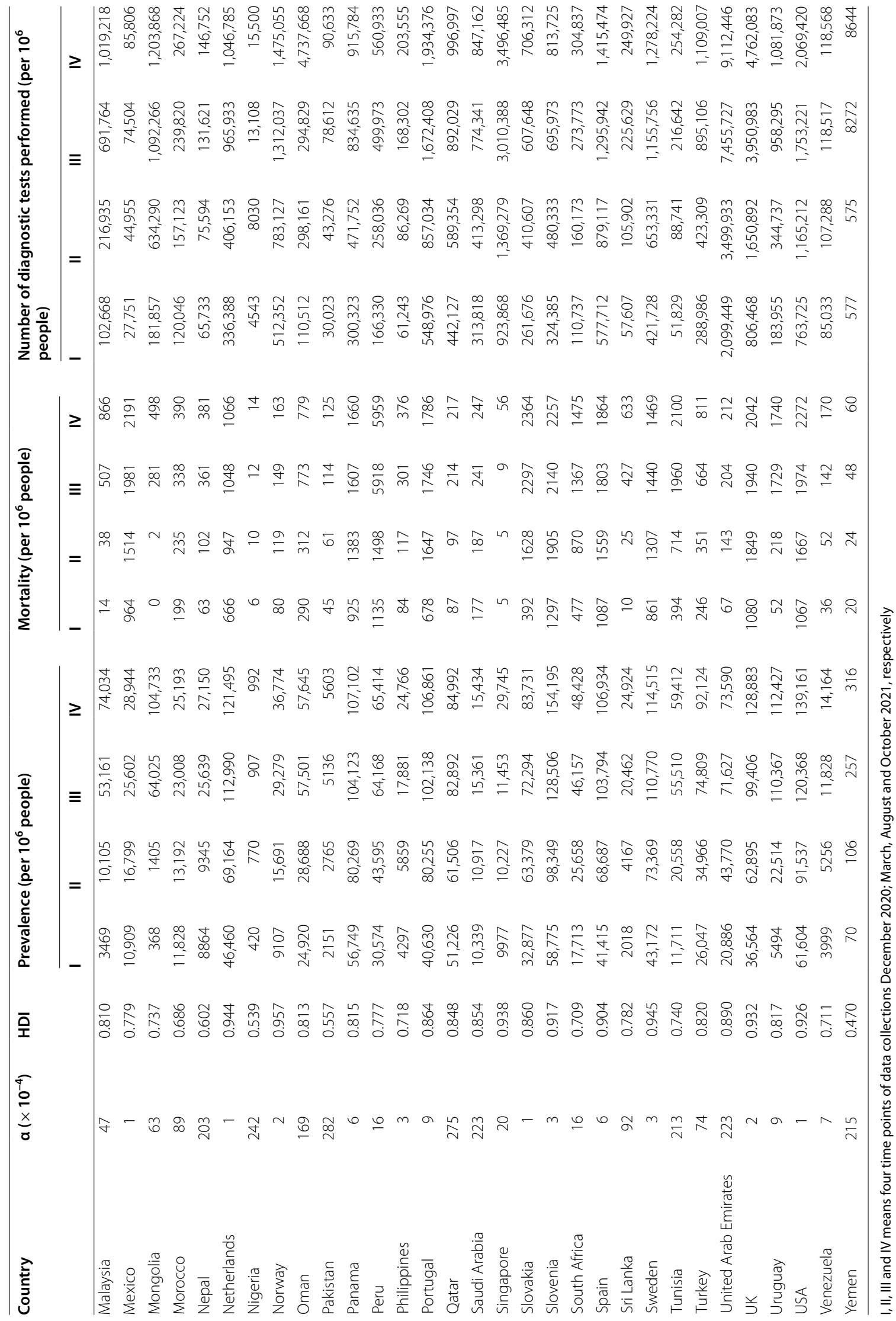


Table 2 Correlation analysis between the studied variables

\begin{tabular}{|c|c|c|c|c|c|c|}
\hline \multirow[t]{2}{*}{ Date/variables } & \multicolumn{2}{|c|}{ SR-prevalence } & \multicolumn{2}{|c|}{ SR-mortality } & \multicolumn{2}{|l|}{ HDI } \\
\hline & $r$ & $P$ & $r$ & $P$ & $r$ & $P$ \\
\hline \multicolumn{7}{|l|}{ End December 2020} \\
\hline Log-a value & -0.395 & 0.001 & -0.556 & $<0.001$ & -0.618 & $<0.001$ \\
\hline SR-performed tests & 0.598 & $<0.001$ & 0.298 & 0.016 & 0.733 & $<0.001$ \\
\hline $\mathrm{HDI}$ & 0.593 & $<0.001$ & 0.468 & $<0.001$ & - & - \\
\hline \multicolumn{7}{|l|}{ March 19, 2021} \\
\hline Log-a value & -0.439 & $<0.001$ & -0.603 & $<0.001$ & -0.618 & $<0.001$ \\
\hline SR-performed tests & 0.625 & $<0.001$ & 0.338 & 0.006 & 0.731 & $<0.001$ \\
\hline $\mathrm{HDI}$ & 0.624 & $<0.001$ & 0.493 & $<0.001$ & - & - \\
\hline \multicolumn{7}{|l|}{ August 31, 2021} \\
\hline Log-a value & -0.372 & 0.002 & -0.498 & $<0.001$ & -0.618 & $<0.001$ \\
\hline SR-performed tests & 0.602 & $<0.001$ & 0.233 & 0.062 & 0.711 & $<0.001$ \\
\hline $\mathrm{HDI}$ & 0.609 & $<0.001$ & 0.399 & 0.001 & - & - \\
\hline \multicolumn{7}{|l|}{ October 25, 2021} \\
\hline Log-a value & -0.404 & 0.001 & -0.506 & $<0.001$ & -0.618 & $<0.001$ \\
\hline SR-performed tests & 0.600 & $<0.001$ & 0.208 & 0.096 & 0.733 & $<0.001$ \\
\hline $\mathrm{HDI}$ & 0.642 & $<0.001$ & 0.407 & 0.001 & - & - \\
\hline
\end{tabular}

df is 63 for all comparisons. SR and Log mean square root- and logarithmic-transformed variables

Table 3 Results of generalized estimation equations for investigation of associations of prevalence and mortality of COVID-19 with the a-values as frequency of consanguineous marriages in the 65 countries around the world

\begin{tabular}{lccr}
\hline Variables & Wald Chi-square & df & $P$-value \\
\hline SR-prevalence as dependent variable & 37.494 & & \\
Time & 7.055 & 3 & $<0.001$ \\
Log-a value & 19.586 & 1 & 0.008 \\
SR-performed tests & 1 & $<0.001$ \\
$\begin{array}{l}\text { SR-mortality as dependent variable } \\
\text { Time }\end{array}$ & 186.856 & 3 & $<0.001$ \\
$\begin{array}{l}\text { Log-a value } \\
\text { Human development } \\
\text { index (HDI) }\end{array}$ & 17.147 & 1 & $<0.001$ \\
\hline
\end{tabular}

infection SARS-CoV-2 or outcome of COVID-19 due to parental consanguinity. Consanguineous marriage results in elevation of homozygosity of mutant alleles with low frequency. Let's assume the frequency of a given mutant allele which is resistance to COVID-19 be equal to $q$ in a given population. The probability of homozygosity for this allele when marriage with biologic relatives is present and absent at population level becomes equal to $q^{2}+a p q$ and $q^{2}$, respectively ( $\alpha$ is the mean of inbreeding coefficient). Therefore, parental consanguinity increases the frequency of mutant homozygotes which they are resistance to COVID-19. Taken together, it is concluded that the present negative association between $\alpha$-value and prevalence/mortality of COVID-19 might be a reflection of elevation of the homozygosity of several mutant alleles involved in resistance against infection of SARS-CoV-2 and/or severe form of COVID-19.

The present study is an ecologic study, and other ecologic studies have some considerations and limitations. It should be noted that frequency of consanguineous marriages and the epidemiologic parameters COVID-19 are not uniformly distributed on different parts of countries. Here average levels of consanguinity and COVID-19 epidemiologic parameters for countries were used for analysis. Hence, the present finding does not mean a causal relationship between parental consanguinity and susceptibility/mortality due to COVID-19. Several case-control and/or cohort studies are needed to confirm the present findings. Finding mutations that induced the resistance to the COVID-19 is also needed.

\section{Conclusions}

The findings of present ecologic study revealed that countries with high frequency of consanguineous marriages, the prevalence of COVID-19 and mortality due to COVID-19 were lower than countries having low level of marriage with relatives. Considering that here the average levels of consanguinity and COVID-19 epidemiologic parameters for countries were used for analysis, the present finding does not mean a causal relationship between parental consanguinity and susceptibility/mortality due to COVID-19. 


\section{Abbreviations}

COVID-19: Coronavirus disease-2019; HDI: Human development index; SARSCoV-2: Severe Acute Respiratory Syndrome Coronavirus 2; SR-transformed:

Square root-transformed.

\section{Acknowledgements}

None.

\section{Authors' contributions}

Conceptualization, data collection, methodology, data analysis, and writing of the manuscript were done by MS. The author read and approved the final manuscript.

\section{Funding}

The author has not declared a specific grant for this research from any funding agency in the public, commercial or not-for-profit sectors.

\section{Availability of data and materials}

All data generated for analysis are presented in Table 1 of the manuscript.

\section{Declarations}

Ethics approval and consent to participate

This is a ecologic study and does not need ethical approval ad consent to participants.

\section{Consent for publication}

None.

\section{Competing interests}

The author declares that he has no competing interests.

Received: 8 June 2021 Accepted: 9 November 2021

Published online: 21 January 2022

\section{References}

1. Bittles $\mathrm{AH}$ (2001) Consanguinity and its relevance to clinical genetics. Clin Genet 60(2):89-98

2. Akrami SM, Osati Z (2007) Is consanguineous marriage religiously encouraged? Islamic and Iranian considerations. J Biosoc Sci 39(2):313-316

3. Saadat M (2007) Consanguinity marriages in Iranian folktales. Commun Genet 10(1):38-40

4. Saadat M (2008) Is consanguineous marriage historically encouraged? J Biosoc Sci 40(1):153-154

5. Saadat M, Ansari-Lari M, Farhud DD (2004) Consanguineous marriage in Iran. Ann Hum Biol 31(2):263-269

6. Rafiee L, Saadat M (2011) Prevalence of consanguineous marriages among Iranian Georgians. J Biosoc Sci 43(1):47-50

7. Saadat M, Zarghami M (2018) Consanguineous marriages among Iranian Mandaeans living in south-west Iran. J Biosoc Sci 50(4):451-456

8. Al-Husain M, Al-Bunyan M (1997) Consanguineous marriages in a Saudi population and the effect of inbreeding on prenatal and postnatal mortality. Ann Trop Paediatrics 17(2):155-160

9. Anvar Z, Namavar-Jahromi B, Saadat M (2011) Association between consanguineous marriages and risk of pre-eclampsia. Arch Gynecol Obstet 283(Suppl 1):5-7

10. Mansour H, Fathi W, Klei L, Wood J, Chowdari K, Watson A, Eissa A et al (2010) Consanguinity and increased risk for schizophrenia in Egypt. Schizophr Res 120(1-3):108-112

11. Nafissi S, Ansari-Lari M, Saadat M (2010) Effect of inbreeding on weight gain of offspring from birth to 12 months after birth, a study from Iran. J Biosoc Sci 42(2):195-200

12. Nafissi S, Ansari-Lari M, Saadat M (2011) Parental consanguineous marriages and age at onset of schizophrenia. Schizophr Res 126(1-3):298-299

13. Saadat M, Vakili-Ghartavol R (2010) Parental consanguinity and susceptibility to drug abuse among offspring, a case-control study. Psychiatry Res 180(1):57-59
14. Saadat M, Zendeh-Boodi Z (2006) Correlation between incidences of selfinflicted burns and means of inbreeding coefficients, an ecological study. Ann Epidemiol 16(6):708-711

15. Bachir S, Aouar A (2019) Study of the impact of consanguinity on abortion and mortality in the population of Beni Abbes (southwestern Algeria). Egypt J Med Hum Genet 20:1. https://doi.org/10.1186/ s43042-019-0004-7

16. Al-Mousa H, Al-Saud B (2017) Primary immunodeficiency diseases in highly consanguineous populations from Middle East and North Africa: epidemiology, diagnosis, and care. Front Immunol 8:678

17. Lyons EJ, Frodsham AJ, Zhang L, Hill AV, Amos W (2009) Consanguinity and susceptibility to infectious diseases in humans. Biol Lett 5(4):574-576

18. Rajaei M, Saadat M (2013) Association between inbreeding coefficient and susceptibility to HIV-1 infection, a case-control study. Germs 3(4):122-125

19. Khalatbari-Soltani S, Cumming RC, Delpierre C, Kelly-Irving M (2020) Importance of collecting data on socioeconomic determinants from the early stage of the COVID-19 outbreak onwards. J Epidemiol Commun Health 74(8):620-623

20. Troumbis AY (2020) Testing the socioeconomic determinants of COVID19 pandemic hypothesis with aggregated human development index. J Epidemiol Commun Health 75(4):414-415

21. Saadat M (2021) Prevalence and mortality of COVID-19 are associated with the L55M functional polymorphism of Paraoxonase 1. Proc Singapore Healthc. https://doi.org/10.1177/20101058211040582

\section{Publisher's Note}

Springer Nature remains neutral with regard to jurisdictional claims in published maps and institutional affiliations.

\section{Submit your manuscript to a SpringerOpen ${ }^{\circ}$ journal and benefit from:}

- Convenient online submission

- Rigorous peer review

- Open access: articles freely available online

- High visibility within the field

- Retaining the copyright to your article

Submit your next manuscript at $\boldsymbol{\nabla}$ springeropen.com 